\title{
Análise dos direcionadores de competitividade sobre a cadeia produtiva de biodiesel: o caso da mamona
}

\author{
Aldara da Silva Césara,*, Mário Otávio Batalha ${ }^{\mathrm{b}}$ \\ a,*aldara@metal.eeimvr.uff.br, UFF, Brasil \\ bdmob@ufscar.br, UFSCar, Brasil
}

\begin{abstract}
Resumo
Entre as várias oleaginosas, a mamona foi identificada pelo Programa Nacional de Produção e Uso do Biodiesel (PNPB) como a oleaginosa ideal para promover desenvolvimento social no nordeste brasileiro. Contudo, a pesquisa revela que a produção dessa matéria-prima não é competitiva para a produção de biodiesel. A pesquisa retratada neste artigo é qualitativa, descritiva e exploratória, tendo utilizado estudo de caso para sua análise. 0 instrumento usado para a coleta de dados foi o questionário semiestruturado com entrevista presencial. Visitas às unidades produtivas também foram feitas, o que permitiu a triangulação dos dados. Dessa forma, este trabalho descreve cada direcionador de competitividade e apresenta uma fotografia da competitividade da produção agrícola e produção industrial da cadeia abordada. A influência de cada direcionador foi avaliada utilizando uma escala Likert. Essa avaliação resultou numa perspectiva da competitividade dos segmentos dessa cadeia agroindustrial.
\end{abstract}

Palavras-chave

Biodiesel. Mamona. Competitividade. Agricultura familiar.

\section{Introdução}

Os custos atuais de produção de biocombustiveis são pouco competitivos em relação aos dos derivados de matérias-primas fósseis (HASS; FOGLIA, 2006; WASSELL JUNIOR; DITTMER, 2006). 0 álcool de cana-de-açúcar no Brasil e o diesel obtido a partir de óleos residuais (PETERS; THIELMANN, 2008) são exceções. Segundo Lensink e Londo (2009), a redução de custos dos biocombustíveis dependerá da experiência cumulativa em tecnologias emergentes que poderão superar essa barreira econômica. Por outro lado, deve-se considerar que a falta de competitividade em custos é parcialmente compensada por reduções de emissões de gases do efeito estufa (DUER; CHRISTENSEN, 2009). Isso ajudaria a explicar o motivo pelo qual, em todo o mundo, ele tem sido produzido sob a proteção de legislações e marcos regulatórios específicos ou de regimes de concessão de subsídios na forma de isenção fiscal (KNOTHE, 2006; PETERS; THIELMANN, 2008; CHARLES et al., 2007).

0 setor de biodiesel tem se desenvolvido rapidamente no Brasil. 0 Programa Nacional de
Produção e Uso do Biodiesel (PNPB) e a legislação pertinente criaram grande demanda por biodiesel e passaram a estimular a produção a partir de diversas oleaginosas.

Além do objetivo mais imediato de fomentar a produção de biodiesel, o PNPB também visa a inclusão social via geração de emprego e renda para pequenos produtores rurais de baixa renda. Para isso, esse programa federal estabeleceu um conjunto de políticas de incentivo que visam inserir de forma sustentável a agricultura familiar nesse processo produtivo.

Entre as várias espécies de oleaginosas disponíveis para a produção de biodiesel, a mamona (Ricinus communis) foi eleita como prioritária pelo governo brasileiro. 0 baixo custo de implantação e produção dessa oleaginosa, bem como sua relativa resistência ao estresse hídrico, permite que a mamoneira se desenvolva em condições adversas de solo e clima, condições características de grande parte do Nordeste brasileiro. Estima-se que cerca de 4,5 milhões de hectares, espalhados por 
406 municípios dessa região, sejam considerados aptos para cultivar essa oleaginosa (BELTRÃO, 2003). Além disso, trata-se de cultura intensiva em mão de obra, o que elevaria a oferta de emprego aos trabalhadores rurais durante dois a três meses do ano. Vale dizer que o Nordeste concentra grande parte da pobreza rural do país, o que justificaria políticas públicas de geração de emprego e renda, via a produção de mamona, destinadas a estes agricultores.

Apesar de promissores, os mecanismos do PNPB têm se mostrado ineficientes para promover a participação efetiva da agricultura familiar de baixa renda nessa cadeia produtiva (CÉSAR, 2009). Essa situação conflita com os objetivos do PNPB, fortemente pautados no desenvolvimento social do pequeno agricultor familiar. Este trabalho tem por proposta avançar na identificação e discussão desses obstáculos de forma a analisar a dinâmica competitiva dos agentes da produção agrícola de mamona e do elo industrial da cadeia produtiva do biodiesel.

Este artigo descreve e analisa a dinâmica de funcionamento dessa cadeia produtiva agroindustrial e também identifica os agentes que dela participam direta e indiretamente. Para tanto, propõe e aplica um modelo de análise de competitividade, para a cadeia produtiva do biodiesel.

\section{Procedimentos metodológicos}

A pesquisa retratada neste artigo é qualitativa e exploratória. Segundo Selltiz et al. (1980), essa abordagem refere-se à descoberta de ideias e percepções, devendo ser suficientemente flexível para considerar todos os aspectos de um fenômeno. Nesse quadro de investigação qualitativa descritiva, empregou-se o método do estudo de caso. Segundo Merriam (1998), o estudo de caso é o método mais apropriado quando o interesse do pesquisador está voltado para uma investigação holística e profunda da realidade a ser investigada. Nesta pesquisa, o caso em análise é a cadeia produtiva do biodiesel no Brasil, com foco nos projetos sociais de mamona desenvolvidos no Nordeste do país. Para a análise das relações entre os agentes dessa cadeia produtiva este trabalho faz uso dessa abordagem descritiva. Essa abordagem tem por finalidade observar, registrar e analisar determinadas características de populações ou fenômenos (JUNG, 2003).

0 instrumento usado para a coleta de dados foi o questionário semiestruturado com entrevista presencial e em profundidade. A revisão teórica sobre o assunto, apoiada pelo modelo de análise adotado, permitiu a construção de um questionário que identificava os direcionadores de competitividade relevantes para essa cadeia produtiva. Em um passo posterior, os entrevistados avaliaram e quantificaram a influência desses direcionadores na competitividade dos segmentos de produção agrícola e industrial da cadeia analisada. A quantificação foi feita utilizando-se uma escala do tipo Likert.

Essa escala de avaliação apresentava uma graduação que variava de +2 para quando o direcionador era "muito favorável" à competitividade a -2 para quando a influência do direcionador era "muito desfavorável" a essa mesma competitividade. Os valores intermediários variaram entre $+1,0$ e -1 , podendo ser classificados respectivamente como "favorável”, “neutro" e "desfavorável” (SILVA; BATALHA, 1999).

Esse procedimento permite a construção de gráficos para uma avaliação visual rápida da condição de competitividade de uma cadeia agroindustrial. A combinação quantitativa dos fatores, de modo a gerar uma avaliação para cada direcionador de competitividade, envolve ainda a atribuição de pesos relativos a esses fatores. Essa atribuição reconhece a existência de graus diferenciados de importância para os diversos fatores analisados. Contudo, é preciso lembrar que essa valoração permite apenas a ordenação dos fatores analisados, ou seja, uma classificação relativa entre eles (SILVA; BATALHA, 1999).

Esses direcionadores de competitividade, bem como os fatores que o compõem, podem ser classificados quanto ao seu grau de controle (controláveis pela firma, pelo governo, quase controláveis e não controláveis). Essa classificação é importante para definir se eventuais obstáculos à competitividade serão alvos de políticas públicas e/ ou privadas (SILVA; BATALHA, 1999).

Juntamente com as entrevistas foram feitas observações diretas em visitas às unidades produtivas. Essas visitas permitiram a realização de um trabalho de "sintonia fina" das informações obtidas nas entrevistas formais e possibilitaram o enriquecimento do conhecimento sobre elementos da dinâmica da cadeia produtiva de biodiesel. Dessa forma, a análise de dados utilizou triangulação de dados visando obter uma múltipla evidência para as afirmações dos entrevistados.

As entrevistas foram realizadas entre outubro de 2008 a junho de 2009. Foram entrevistados 63 atores-chave da cadeia. Dentre esses, 16 entrevistados pertenciam a órgãos públicos; cinco eram profissionais de bancos envolvidos com o crédito rural; 15 representaram as opiniões das empresas produtoras de biodiesel; três atuavam junto às empresas da ricinoquímica; seis eram oriundos de cooperativas agrícolas, dois trabalhavam 
em ONGs ligadas ao tema e 16 entrevistados eram produtores agrícolas.

Os resultados da pesquisa de campo foram utilizados para identificar os principais problemas que condicionam a competitividade dessa cadeia agroindustrial e suas causas subjacentes. 0 resultado direto dessa analise é a proposição de medidas de intervenção para a melhoria do desempenho do sistema agroindustrial em foco.

\section{Referencial teórico}

A literatura apresenta diversas definições para o termo competitividade (FISCHER; SCHORNBERG, 2007). Na tentativa de encontrar um conceito unificado, Aiginger (2006, p. 64) definiu a competitividade como sendo "a habilidade de um país ou uma região em criar bem-estar". Para Landau (1992, p. 15), a competitividade de uma nação pode ainda ser vista como sendo

[...] a capacidade de uma nação sustentar uma taxa de crescimento e padrão de vida adequado para seus cidadãos enquanto proporciona emprego sem reduzir o potencial de crescimento e o padrão de vida das gerações futuras [...].

Entretanto, para Farina (1999), o termo competitividade compreende tantas facetas de um mesmo problema que dificilmente se poderia estabelecer uma definição que fosse simultaneamente útil e abrangente. Para Pinheiro, Moreira e Horta (1992), as diferentes variáveis e indicadores associados ao termo resultam em ambiguidades e dificultam a sua compreensão. Segundo Jank (1996), dada a diversidade de variáveis que caracterizam as economias modernas e o comércio entre as nações, o tema tem se tornando cada vez mais complexo.

Essa diversidade de definições deriva, em grande parte, do grande conjunto de áreas de conhecimento que se apropriaram do termo para conduzir suas pesquisas e realizar suas análises. Assim, a aplicação do termo vai da economia à gestão, passando por áreas variadas como a sociologia, a gestão ambiental, entre outras. De forma geral, a competitividade pode ser definida como a capacidade sustentada de um sistema produtivo manter ou aumentar sua posição no mercado (MARTIN et al., 1991; FERRAZ et al., 1996; SILVA; BATALHA, 1999). Um dos problemas que decorre desse conceito é a definição do sistema produtivo a ser considerado. Essa definição é importante, pois ela delimita o foco das análises. A literatura aponta três níveis diferentes de análise: a competitividade da firma, a competitividade do setor ou a competitividade de uma dada região ou país.
Entre o nível micro e macroanalítico da competitividade situa-se a análise setorial. Esse tipo de análise poderia ser considerado uma mesoanálise situada entre as questões macroeconômicas e as microeconômicas surgidas do comportamento das firmas. Pesquisadores em agribusiness são numerosos em situar essa análise mesoanalítica ao nível das cadeias agroindustriais de produção (VAN DUREN et al., 1991; VAN DUREN; MCKAY, 1994; FARINA, 1999; SILVA; BATALHA, 1999; SILVA; SOUZA FILHO, 2007; BATALHA; SOUZA FILHO, 2009). Para esses autores, a competitividade agroindustrial é o resultado não somente do comportamento individual das firmas, mas também do próprio sistema - nesse caso, a cadeia agroindustrial -, onde a mesma está inserida. Dessa forma, a competitividade da firma seria tributária das suas relações com os outros agentes do sistema.

A abordagem sistêmica que permeia esse estudo fundamenta-se em estudos originalmente desenvolvidos no campo da biologia e engenharia. Esses se dividiram em dois conjuntos principais de ideias que impulsionaram os estudos dos problemas agroindustriais: noções de commodity system approach (CSA) e de analyse de filière, também chamada de cadeia de produção agroindustrial (BATALHA; SILVA, 2007). A abordagem sistêmica é subjacente a praticamente todos os estudos que se debruçam sobre a competitividade de SAls definidos a partir de uma dada cadeia de produção (VAN DUREN et al., 1991; VAN DUREN; MCKAY, 1994; SILVA; BATALHA, 1999; FARINA, 1999; BATALHA; SOUZA FILHO, 2009).

A importância da análise do tipo mesoanalítica é o fato de que além de estudar as mudanças estruturais e funcionais dos subsistemas, estuda sua interdependência em um sistema integrado. Concomitantemente, o systemic approach tem sido ferramenta útil na averiguação das várias facetas que permeiam a dinâmica de funcionamento de um sistema agroindustrial (BATALHA; SILVA, 2007).

Segundo Staatz (1997), o enfoque sistêmico é guiado por cinco conceitos-chave, a saber: verticalidade (as características de um elo influenciam os demais); orientação por demanda (a demanda gera informações que determinam os fluxos de produtos ao longo da cadeia); coordenação dentro da cadeia (as formas de coordenação entre os agentes estrutura de governança - são de fundamental importância para a dinâmica de funcionamento das cadeias produtivas); competição entre sistemas (o sucesso da empresa dependerá da habilidade de gerenciamento das integrações dos relacionamentos dos subsistemas, que claramente mostram 0 paradigma da sociedade moderna, na qual a empresa não mais compete sozinha e sim através de todo o 
sistema); e alavancagem (pontos-chave que podem propiciar a melhoria da eficiência de um grande número de participantes de uma só vez).

Outra característica importante dessa abordagem é ela permitir analisar as firmas que compõem uma cadeia de produção agroindustrial de forma interdependente, isto é, para que uma empresa seja competitiva, as demais (empresas fornecedoras e empresas supridas) também têm de ser competitivas (SILVA; BATALHA, 1999). Dessa maneira, o enfoque sistêmico permite maior compreensão na análise de competitividade por considerar a complexidade que se origina nos impactos individualizados e combinados de várias ações, o que tem contribuído para a difusão dessa análise em diversos trabalhos de renomadas instituições públicas e privadas (BATALHA; SOUZA FILHO, 2007).

Ao considerar o caráter sistêmico dos fatores que influenciam a competitividade das cadeias produtivas, Van Duren et al. (1991) desenvolveram um referencial metodológico para análise da competitividade do agronegócio canadense, no qual consideraram os elementos característicos da agroindústria. Nesse trabalho, as autoras levaram em conta o caráter sistêmico dos fatores que influenciavam a competitividade das cadeias e os dividiram em quatro grandes grupos:

1) Fatores controláveis pelo governo: são ações que, como diz o nome, são controláveis pelo governo; portanto, não podem ser modificadas por uma ação específica da firma ou cadeia - apesar de os fatores estarem sujeitos à pressão dos agentes da indústria. São exemplos desses fatores: políticas fiscais e monetárias, política educacional e leis de regulamentação do mercado.

2) Fatores controláveis pela firma: são aqueles que podem ser modificados pelas firmas, como estratégia, produtos, tecnologia, políticas de recursos humanos, pesquisa e desenvolvimento etc.

3) Fatores quase-controláveis: são os fatores que não podem ser modificados diretamente pelas firmas e pelas ações governamentais; no entanto, experiências têm demonstrado que os mesmos podem ser amenizados a partir de maior planejamento estratégico decorrente de coordenação da cadeia. Exemplos de alguns desses fatores são: ameaças de novos concorrentes, competição entre os agentes da cadeia, poder de barganha entre fornecedores e clientes e condições de demanda.

4) Fatores não controláveis: são os fatores naturais e climáticos, cujos impactos têm sido cada vez mais reduzidos por meio de melhores informações (previsão do tempo) e pesquisas direcionadas com desenvolvimento de novas tecnologias - como a biotecnologia (VAN DUREN; MCKAY, 1994).
A análise de competitividade proposta por Van Duren et al. (1991) estabelece como indicadores de competitividade: parcela de mercado e lucratividade. Essa mensuração pode ser feita por meio do emprego de informações estatísticas de domínio público ou privado e/ou dados levantados diretamente junto aos agentes participantes do sistema agroindustrial.

De acordo com Martin et al. (1991), o efeito combinado de um conjunto de fatores tem como resultado certa condição de competitividade para um dado espaço de análise. Cada um deste conjunto de fatores, agrupados segundo suas características de base e os impactos que têm na competitividade, pode ser definido como sendo um "direcionador de competitividade". Os direcionadores de competitividade devem ser capazes de refletir os aspectos essenciais que determinam as causas de competitividade de um dado espaço de análise. Este espaço de análise pode ser um país ou região, um determinado setor industrial, uma cadeia produtiva ou ainda uma firma específica. Os "direcionadores de competitividade" englobam itens que muitas vezes não são facilmente mensuráveis de forma direta, mas que sabidamente podem interferir na competitividade de um sistema de produção.

De acordo com Batalha e Silva (2007), direcionadores de competitividade aplicados aos sistemas agroindustriais de produção devem possuir um caráter mesoanalítico, ou seja, eles devem permitir a análise estrutural e funcional dos subsistemas (agentes) e sua interdependência em um sistema integrado (cadeia produtiva). Isso remete diretamente ao enfoque sistêmico que pressupõe a participação coordenada dos atores do Sistema Agroindustrial (SAI) e das indústrias que dão suporte a esse sistema produtivo, chamadas indústrias de apoio.

0 modelo proposto por César (2009) sugere oito direcionadores para a análise da cadeia produtiva, que se desdobram em vários subfatores, de acordo com as especificidades do segmento (elo) analisado (Figura 1). Dessa forma, oito direcionadores de competitividade potencial foram selecionados para as análises dos SAls (elo agrícola e elo industrial): fatores macroeconômicos, programas e políticas setoriais, tecnologia, estrutura de mercado, estrutura de governança, gestão, recursos produtivos e infraestrutura.

\section{Políticas de incentivo à cadeia produtiva brasileira de biodiesel}

A ação mais importante do Programa Nacional de Produção e Uso de Biodiesel (PNPB) foi a instituição da Lei n. ${ }^{\circ}$ 11.097/2005 (BRASIL, 2005a). 


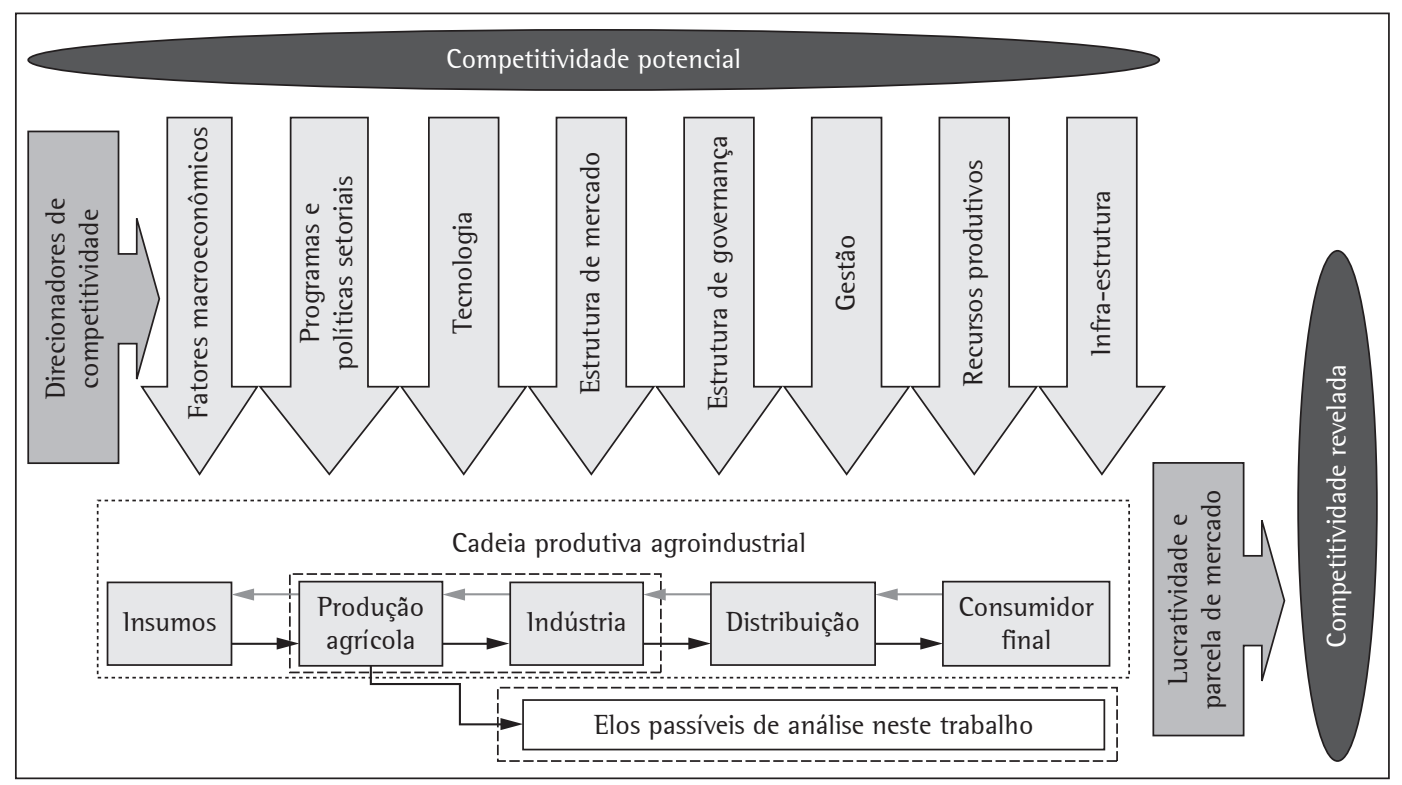

Figura 1. Ação dos direcionadores de competitividade sobre a cadeia produtiva agroindustrial. Fonte: adaptado de Batalha e Souza Filho (2009) e Silva e Souza Filho (2007).

Essa lei estabeleceu a adição de $2 \%$ de biodiesel ao óleo diesel produzido (B2) em território brasileiro a partir de 2008 (BRASIL, 2005a). Desde então, a produção de biodiesel tem respondido a essa demanda e o setor tem se desenvolvido rapidamente. A Resolução n. ${ }^{\circ}$ 6/2009/CNPE determinou que a porcentagem de $5 \%$, prevista para 2013 , vigorasse já a partir de $1^{\circ}$ de janeiro de 2010 .

Além da obrigatoriedade de adição de biodiesel ao diesel de petróleo, a mesma lei criou outros mecanismos para incentivar a inclusão social de pequenos agricultores, como o "Selo Combustível Social” (SCS) (GARCEZ; VIANNA, 2009).

O SCS prevê acordos de comercialização entre agricultores familiares que garantam uma renda justa e sustentável a esses produtores. Fornecer capacitação e assistência técnica aos pequenos produtores é também condição necessária à obtenção do SCS. Esses requisitos são estabelecidos e fiscalizados pelo Ministério do Desenvolvimento Agrário (MDA) (BRASIL, 2009a, b). As relações comerciais entre as empresas que produzem biodiesel e os agricultores familiares estão representadas na Figura 2.

0 SCS tem duração de cinco anos contados a partir de $1^{\circ}$ de janeiro do ano subsequente à sua concessão. Para obtê-lo, a empresa deve adquirir um percentual mínimo de matéria-prima de agricultores familiares. Essa parcela é estipulada pelo MDA e pode ser diferenciada de acordo a região do país onde a empresa está instalada. Num

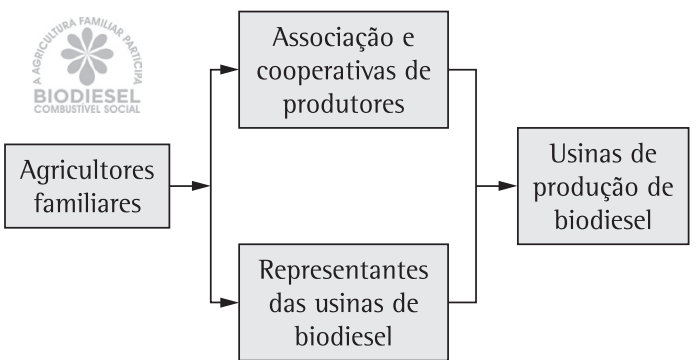

Figura 2. Arranjos produtivos com mamona (comercialização) via selo combustível social.

primeiro momento esses valores foram definidos pela Instrução Normativa (IN) n. ${ }^{\circ}$ 01/2005 do MDA como 50\% para as regiões Nordeste e semiárido, $30 \%$ para as regiões Sul e Sudeste e 10\% para as regiões Norte e Centro-oeste (BRASIL, 2005b). Conforme a Lei n. ${ }^{\circ} 11.116 / 2005$, o percentual mínimo de aquisição de matéria-prima originária de agricultores familiares pelas usinas é calculado em relação ao custo de aquisições totais de matérias-primas.

0 selo traz vantagens de ordem tributária, permite o acesso da empresa aos leilões da Agência Nacional do Petróleo (ANP), favorece a obtenção de melhores condições de financiamento junto a bancos públicos e serve como instrumento de marketing positivo para as empresas (BRASIL, 2005b). 
Os leilões, que operam sob responsabilidade da ANP, foram criados para estimular o mercado de biodiesel antes do início da obrigatoriedade do B2 (POUSA et al., 2007). Outra prioridade das compras públicas via leilões é fomentar a integração entre o produtor de biodiesel e os produtores familiares, tendo em vista que o acesso à maioria desses leilões é facultado somente a empresas que possuem o SCS. Entretanto, sua principal função atual é garantir a compra do biodiesel necessário para que as metas do PNPB sejam atendidas.

Vale ressaltar que, com o objetivo de amenizar as dificuldades da implementação do SCS, o governo instituiu em 2009 novas regras para a sua concessão que não foram analisadas neste trabalho, já que no período da entrevista esses valores ainda não estavam efetivados (CÉSAR; BATALHA, 2010). As novas normas (IN n. ${ }^{\circ} 01 / 2009$ ) estabelecem novo percentual mínimo de aquisições de matéria-prima de agricultores familiares pelas usinas - de 10\% para a safra 2009/2010 e de 15\% a partir da safra 2010/2011 para as aquisições provenientes das regiões Norte e Centro-oeste. Para as regiões Sul, Sudeste, Nordeste e o semiárido esse percentual é de 30\% (BRASIL, 2009a). Uma diferença importante em relação às regras antigas é que esse custo de aquisição das matérias-primas pago pelas usinas passa a incluir também os gastos com análises do solo, fornecimento de insumos de produção pelas empresas (desde que não oriundos de recursos públicos) e algumas despesas com assistência e capacitação técnica dos agricultores familiares.

\section{Análise dos direcionadores de competitividade para a produção de biodiesel mamona}

\subsection{Elo industrial: fabricação de biodiesel}

A Figura 3 apresenta o efeito agregado da análise de cada direcionador de competitividade sobre a indústria de biodiesel. A Tabela 1 apresenta o grau de controle dos subfatores ponderados nesta pesquisa, a relevância e o peso com que cada qual afeta cada direcionador de competitividade para o segmento industrial dessa cadeia produtiva.

- Políticas setoriais: as políticas setoriais são favoráveis para a indústria brasileira de biodiesel. Em todo o mundo a demanda por biodiesel tem sido moldada por políticas públicas que fornecem benefícios fiscais e estipulam misturas obrigatórias com o diesel originado do petróleo (CHARLES et al., 2007; PETERS; THIELMANN, 2008). No Brasil não é diferente.
O Brasil, assim como outros países, estabeleceu um conjunto de políticas de incentivos para o biodiesel a fim de compensar a falta de competitividade dessa cadeia produtiva. Desde o lançamento do PNPB, a produção de biodiesel tem crescido rapidamente. Atualmente, a adição obrigatória é de 5\% de biodiesel ao diesel de petróleo. 0 que diferencia o PNPB de iniciativas de outros países é a utilização da produção de biodiesel para a inclusão social de pequenos agricultores. No entanto, a iniciativa do PNPB vem esbarrando nos elevados custos de transação relacionados ao gerenciamento de um grande número de pequenas propriedades rurais.

As entrevistas realizadas com profissionais da cadeia produtiva de biodiesel no Brasil revelaram que apenas três empresas de biodiesel ainda desenvolvem algum trabalho com ações sociais vinculadas à produção de mamona. 0 acesso aos leilões da ANP e os incentivos fiscais são os principais motivos que têm levado as empresas produtoras de biodiesel a continuar fomentando esses projetos. Paradoxalmente, a cota inicial de 50\% do custo de aquisição de matéria-prima originada da agricultura familiar pelas usinas gerou obstáculos ao sucesso de projetos sociais no Nordeste do Brasil, especialmente nas regiões do semiárido. Em muitos casos, os benefícios fiscais associados ao SCS não compensaram os esforços das empresas produtoras de biodiesel em trabalhar com a precária estrutura produtiva disponível para essa oleaginosa. Nessa situação, os investimentos privados na produção, organização e gestão apresentaram-se insuficientes para garantir o funcionamento adequado desses arranjos produtivos. Algumas empresas simplesmente abandonaram os projetos com mamona e outras deslocaram seus projetos para outras regiões do país (muitas vezes para trabalharem com outras matérias-primas), nas quais

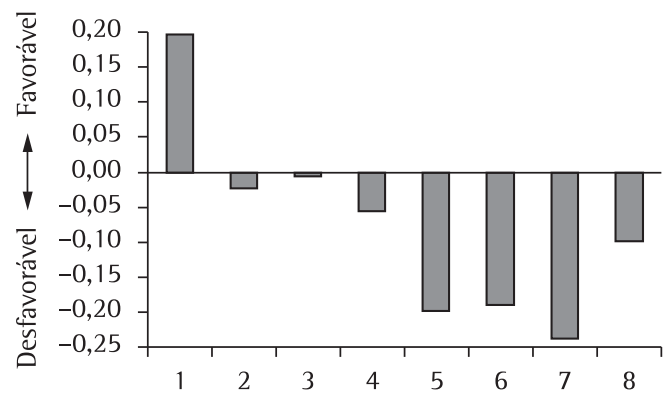

Figura 3. Direcionadores de competitividade que impactam a indústria de biodiesel. 1) Políticas setoriais, 2) fatores macroeconômicos, 3) tecnologia, 4) gestão, 5) recursos produtivos, 6) estrutura de mercado, 7) estrutura de governança e 8) infraestrutura. 
Tabela 1. Direcionadores de competitividade que impactam a indústria de biodiesel.

\begin{tabular}{|c|c|c|c|c|c|c|c|c|}
\hline \multirow{2}{*}{ Direcionadores / fatores } & \multicolumn{4}{|c|}{ Grau de controle ${ }^{1}$} & \multirow{2}{*}{$\mathrm{PD}^{2}$} & \multirow{2}{*}{ Relev. $^{3}$} & \multirow{2}{*}{$\mathrm{PF}^{4}$} & \multirow{2}{*}{ Resultado } \\
\hline & $\mathrm{CF}$ & CG & QC & NC & & & & \\
\hline POLÍTICAS SETORIAIS & $x$ & $x$ & & & & & 100 & 0,198 \\
\hline Lei n. 11.097 & & $x$ & & & & $\mathrm{MF}$ & 50 & 0,18 \\
\hline SCS & $X$ & $x$ & & & 18 & $\mathrm{~F}$ & 30 & 0,054 \\
\hline Operacionalização do selo social & & $x$ & & & & $\mathrm{D}$ & 20 & $-0,036$ \\
\hline FATORES MACROECONÔMICOS & $X$ & $X$ & $X$ & & & & 100 & $-0,0225$ \\
\hline Preço do petróleo & & $x$ & $x$ & & & MD & 30 & $-0,09$ \\
\hline Taxa de câmbio & & $x$ & $x$ & & & $\mathrm{D}$ & 5 & $-0,0075$ \\
\hline Tributação & & $x$ & & & 15 & $\mathrm{~F}$ & 20 & 0,03 \\
\hline Crédito & & $x$ & $X$ & & & $\mathrm{~F}$ & 30 & 0,045 \\
\hline Endividamento & $\mathrm{X}$ & $x$ & & & & $\mathrm{~N}$ & 15 & 0 \\
\hline TECNOLOGIA & $x$ & $\mathrm{X}$ & & & & & 100 & $-0,005$ \\
\hline Flexibilidade da planta quanto à matéria-prima & $x$ & & & & & $\mathrm{~F}$ & 15 & 0,015 \\
\hline Qualidade do biodiesel de mamona & $\mathrm{X}$ & & & & & $\mathrm{D}$ & 25 & $-0,025$ \\
\hline Usos da torta (de mamona) & $x$ & & & & 10 & $\mathrm{~F}$ & 15 & 0,015 \\
\hline Usos da glicerina (geral) & $\mathrm{X}$ & & & & & MD & 25 & $-0,05$ \\
\hline Pesquisa e desenvolvimento & $x$ & $X$ & & & & $\mathrm{MF}$ & 20 & 0,04 \\
\hline GESTÃo & $x$ & $\mathrm{X}$ & $\mathrm{X}$ & & & & 100 & $-0,056$ \\
\hline Custo & $\mathrm{X}$ & & $\mathrm{X}$ & & & $\mathrm{N}$ & 30 & 0 \\
\hline Assistência técnica & $x$ & $X$ & $x$ & & 8 & $\mathrm{D}$ & 40 & $-0,032$ \\
\hline Planejamento estratégico & $\mathrm{X}$ & & & & & $\mathrm{D}$ & 30 & $-0,024$ \\
\hline RECURSOS PRODUTIVOS & $\mathrm{X}$ & $\mathrm{X}$ & $\mathrm{X}$ & & & & 100 & $-0,198$ \\
\hline Matéria-prima & $x$ & $x$ & $\mathrm{X}$ & & & MD & 75 & $-0,18$ \\
\hline Álcool & $x$ & $\mathrm{X}$ & $x$ & & 12 & $\mathrm{D}$ & 15 & $-0,018$ \\
\hline Outros: catalisador; energia, vapor etc. & $x$ & & $x$ & & & $\mathrm{~N}$ & 10 & 0 \\
\hline ESTRUTURA DE MERCADO & $\mathrm{X}$ & $\mathrm{X}$ & $\mathrm{X}$ & & & & 100 & $-0,189$ \\
\hline Deslocamento espacial & $\mathrm{X}$ & & & & & MD & 35 & $-0,098$ \\
\hline Escala de produção & $\mathrm{X}$ & $x$ & & & 14 & $\mathrm{D}$ & 35 & $-0,049$ \\
\hline Nivel de concentração & & & $x$ & & & MD & 30 & $-0,042$ \\
\hline ESTRUTURA DE GOVERNANÇA & $X$ & & $\mathrm{X}$ & & & & 100 & $-0,238$ \\
\hline Relação com os agricultores familiares & $\mathrm{X}$ & & $\mathrm{X}$ & & & MD & 20 & $-0,056$ \\
\hline Relação com as cooperativas & $\mathrm{X}$ & & $x$ & & 14 & $\mathrm{D}$ & 30 & $-0,042$ \\
\hline Intermediários & $x$ & & $x$ & & & MD & 50 & $-0,14$ \\
\hline INFRAESTRUTURA & $\mathrm{X}$ & $\mathrm{X}$ & & & & & 100 & $-0,099$ \\
\hline Condições das rodovias & & $x$ & & & & MD & 70 & $-0,126$ \\
\hline Disponibilidade de tanques & $X$ & & & & $y$ & $\mathrm{~F}$ & 30 & 0,027 \\
\hline
\end{tabular}

'Grau de controle: CF - Controlável pela Firma, CG - Controlável pelo Governo, QC - Quase Controlável e NC - Não Controlável. ${ }^{2}$ Peso D - Peso do direcionador no total agregado. ${ }^{3}$ Relevância - Avaliação: MD - Muito Desfavorável (valor $=-2$ ), D - Desfavorável (valor $=-1$ ), $\mathrm{N}-$ Neutro (valor $=0$ ), F - Favorável (valor $=+1$ ), MF - Muito Favorável (valor $=+2$ ). ${ }^{4}$ Peso F - Peso do fator sobre o direcionador.

os riscos e as cotas exigidas de matérias-primas provindas da agricultura familiar eram menores.

- Fatores macroeconômicos: a baixa cotação do petróleo impacta negativamente a expansão de biodiesel. No entanto, esse fator não tem impedido o desenvolvimento dessa nova cadeia produtiva (POUSA et al., 2007). A facilidade para o acesso ao crédito é um aspecto que compensa esse cenário negativo. A tributação para a indústria de biodiesel é favorável, pois não há incidência de Imposto Sobre Produtos Industrializados (IPI) sobre o biodiesel e as empresas ainda podem usufruir de descontos diferenciados no pagamento do PIS/ PASEP.

- Tecnologia: o biodiesel de mamona apresenta restrições tecnológicas. Apesar de as plantas possuírem certa flexibilidade, elas não são capazes de produzir adequadamente a partir de mamona. Há dificuldade quanto ao enquadramento do biodiesel de mamona às normas exigidas pela ANP, principalmente no que se refere a sua viscosidade. A pesquisa indica que a glicerina originada no processo de fabricação de biodiesel também é um gargalo nesse processo. Ainda não foram encontradas soluções econômica e ambientalmente 
viáveis para a utilização dos grandes volumes de glicerina gerados pela produção do biodiesel. Contudo, algumas empresas têm investido no desenvolvimento de processos de produção que visam transformar a glicerina em alguns tipos de polímeros, especialmente polipropilenos. Em decorrência das perspectivas de expansão do segmento de biodiesel, há esforços para tornar o processo industrial mais eficiente, tanto nas reações de conversão do óleo (ou gordura) em biodiesel, quanto para melhor aproveitamento da glicerina, o que compensaria o impacto desse direcionador no elo analisado.

- Gestão: a gestão de custos é considerada um aspecto desfavorável à competitividade da cadeia. A gestão de suprimento de óleos das usinas consultadas nesta pesquisa não consolidou uma rede de fornecedores oriundos da agricultura familiar nas regiões nas quais estão instaladas. 0 conjunto de incentivos às organizações dos pequenos agricultores familiares somente foi estabelecido após a inauguração das unidades de processamento, mas ainda apresenta indefinições e problemas importantes. Problemas de assistência técnica fornecida pelo governo e a inexperiência das empresas privadas de produção nesse campo elevaram os custos de produção. A assistência técnica, seja prestada pelas empresas privadas via contratação de técnicos particulares ou pelo Estado, continua problemática. Esse ainda é um gargalo importante dessa cadeia. É provável que essa situação se altere com a Instrução Normativa (IN) n. ${ }^{\circ}$ 01/2009 (BRASIL, 2009a). Essa IN estabelece, dentre outras notas, que a empresa pode incluir certos gastos necessários à viabilidade desses projetos (como despesas com capacitação técnica, análises de solo e fornecimento de alguns insumos) no custo de aquisição da matéria-prima pela empresa. Com isso o SCS pode ser obtido a partir da compra de menor percentagem de matéria-prima oriunda dos pequenos agricultores familiares.

- Recursos produtivos: esse direcionador também é desfavorável. 0 preço do óleo vegetal é determinante no processo de escolha da matériaprima que será utilizada para a produção de biodiesel (DEMIRBAS, 2007). 0 óleo vegetal representa entre $75 \%$ e $85 \%$ do custo final do biodiesel (BRASIL, 2004). 0 preço do óleo de mamona é superior ao de outros óleos vegetais e ao do diesel mineral, motivo pelo qual seu uso como carburante pode parecer um paradoxo. 0 óleo de mamona é considerado um produto nobre e possui características que lhe são únicas (BELTRÃO et al., 2007). Esse óleo representa menos que $0,15 \%$ de todo óleo de sementes negociado no mercado internacional (SCHOLZ; SILVA, 2008). A baixa oferta do óleo atinge mesmo o Brasil, terceiro maior produtor mundial de óleo de mamona. A maior empresa de ricinoquímica brasileira teve que recorrer às importações para atender aos pedidos firmados nos últimos anos, chegando a importar, em 2007 e 2008, um montante de 10 mil toneladas desse óleo (BRASIL, 2009b). A baixa oferta do óleo de mamona no mercado mundial e suas especificidades técnicas contribuem para seus elevados preços no mercado internacional.

As fábricas brasileiras de biodiesel não têm incluído a mamona, pelos motivos já citados, entre as matérias-primas que vêm processando. Essa situação tem feito com que algumas empresas de biodiesel atuem como grandes intermediárias da cadeia de ricinoquímica, não processando a mamona adquirida para a produção de biodiesel. Cabe destacar que a lei n. ${ }^{0} 11.097$ (BRASIL, 2005a) reza que o biodiesel deve ser processado preferencialmente (e não obrigatoriamente) a partir de matérias-primas produzidas por agricultor familiar.

- Estrutura de mercado: a estrutura de mercado é desfavorável para as empresas de biodiesel. 0 biodiesel é adquirido basicamente por uma empresa distribuidora que faz com que o poder de mercado das usinas processadoras seja praticamente nulo.

- Estrutura de governança: cumpre observar que, segundo as empresas fabricantes de biodiesel, o gerenciamento de um número muito grande de agricultores familiares à montante da cadeia dificulta o desenvolvimento de um vínculo mais estreito com esses mesmos produtores. A pesquisa aponta que são enormes as dificuldades enfrentadas pelas empresas para concretização dos contratos junto ao agricultor familiar, embora acordos firmados com as cooperativas sejam mais favoráveis que os firmados diretamente com os agricultores familiares. 0 trabalho de campo revelou que contratos celebrados diretamente entre os agricultores familiares e as empresas dificilmente são cumpridos. Por outro lado, a organização dos agricultores familiares em cooperativas e associações é muito frágil. Ainda que existam sindicatos de trabalhadores rurais e algumas cooperativas inseridas nesse segmento, essas organizações parecem não ter capital social suficiente para auxiliar de forma decisiva a implementação dos projetos sociais e de produção das usinas. Uma das lacunas, talvez a mais importante para modificar essa situação, é a necessidade de capacitação de agricultores familiares que possam coordenar esses arranjos mais eficientemente. A figura do intermediário na comercialização da mamona é muito desfavorável nesse cenário, pois seu alto poder de mercado permite que este aja como um especulador no mercado dessa matéria-prima. 
- Infraestrutura: as usinas, apesar de possuírem boa infraestrutura, não têm operado com mamona e, mesmo assim, a produção de biodiesel a partir de outras oleaginosas está aquém da sua capacidade produtiva. A baixa oferta de mamona também afeta as empresas de ricinoquímica que têm adquirido mamona de projetos sociais do biodiesel. Essas empresas têm importado óleo de mamona para atender os contratos já firmados.

0 Quadro 1 apresenta algumas medidas que vêm sendo tomadas, bem como proposições, para amenizar os entraves apontados nesse elo da cadeia.

\subsection{Elo agrícola: produção de mamona}

A Figura 4 apresenta o efeito agregado da análise de cada direcionador de competitividade sobre a produção agrícola de mamona. A Tabela 2 apresenta o grau de controle dos subfatores, a relevância e o peso com que cada qual afeta cada direcionador de competitividade para o segmento industrial dessa cadeia produtiva.

\section{- Políticassetoriais:as políticassetoriaisseapresentam} favoráveis à produção agrícola da mamona. Embora a criação do SCS tenha trazido ganhos potenciais para o produtor, sua operacionalização mostrou-se incapaz de contribuir decisivamente para a melhoria de projetos sociais baseados nesse produto. Há incentivos diferenciados em relação às demais oleaginosas, no entanto eles não têm sido suficientes para promover o desenvolvimento de arranjos produtivos baseados na mamona destinada à produção de biodiesel. Por todos esses motivos, algumas indústrias e associações de produtores têm migrado para culturas mais rentáveis e para outras regiões nas quais as cotas exigidas pelo selo sejam menores e, portanto, com maior viabilidade econômica.

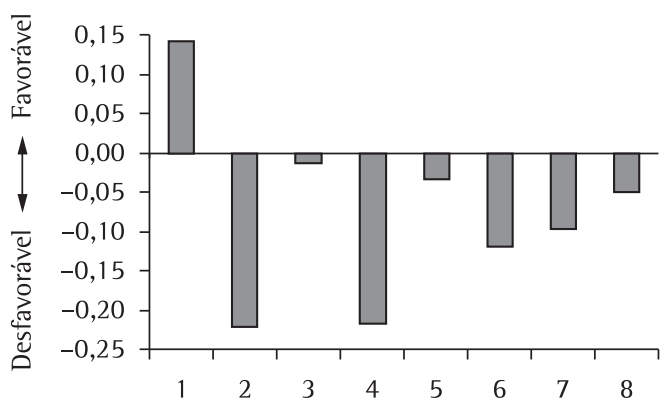

Figura 4. Direcionadores de competitividade que impactam a indústria de biodiesel. 1) Políticas setoriais, 2) fatores macroeconômicos, 3) tecnologia, 4) gestão, 5) recursos produtivos, 6) estrutura de mercado, 7) estrutura de governança e 8) infraestrutura.

Quadro 1. Principais problemas enfrentados pela indústria e proposições.

\begin{tabular}{|c|c|c|}
\hline Principais problemas & Situação atual & Proposições / desafios \\
\hline $\begin{array}{c}\text { Baixo preço do } \\
\text { petróleo em relação ao } \\
\text { biodiesel }\end{array}$ & $\begin{array}{c}\text { As baixas cotações de petróleo são } \\
\text { desfavoráveis para o desenvolvimento dessa } \\
\text { nova cadeia produtiva. }\end{array}$ & $\begin{array}{l}\text { Manutenção e aprimoramento dos subsídios } \\
\text { federais para continuar incentivando a } \\
\text { estruturação do setor. }\end{array}$ \\
\hline $\begin{array}{l}\text { Preço do óleo de } \\
\text { mamona }\end{array}$ & $\begin{array}{c}\text { A baixa oferta e o alto preço do óleo de } \\
\text { mamona no mercado internacional contribuem } \\
\text { negativamente para a competitividade de um } \\
\text { biodiesel feito a partir dessa matéria-prima. }\end{array}$ & $\begin{array}{l}\text { Aumentar a oferta dessa oleaginosa poderia } \\
\text { diminuir o preço do óleo de mamona. } 0 \text { aumento } \\
\text { da oferta poderia ser feito pelo expansão da } \\
\text { cultura e de sua produtividade. }\end{array}$ \\
\hline $\begin{array}{l}\text { Restrições tecnológicas: } \\
\text { do processo, produto e } \\
\text { co-produto }\end{array}$ & $\begin{array}{c}\text { Dificuldades no enquadramento do biodiesel } \\
\text { às normas exigidas, em decorrência } \\
\text { principalmente da elevada viscosidade do óleo. } \\
\text { A glicerina, originada no processo de } \\
\text { fabricação de biodiesel também é um gargalo } \\
\text { nesse processo. }\end{array}$ & $\begin{array}{c}\text { Desenvolvimento de tecnologias adequadas } \\
\text { de produção de biodiesel. Um desafio seria } \\
\text { desenvolver cultivares que resultem em óleos } \\
\text { com viscosidades menores que as disponíveis no } \\
\text { mercado. } \\
\text { Desenvolvimento de pesquisas visando o melhor } \\
\text { aproveitamento da glicerina. }\end{array}$ \\
\hline Assistência técnica & $\begin{array}{l}\text { A assistência técnica aos produtores rurais é } \\
\text { deficiente. A falta de recursos compromete a } \\
\text { padronização desse serviço nas propriedades. }\end{array}$ & $\begin{array}{l}\text { Investimento em treinamento para capacitar } \\
\text { o corpo técnico, tanto no que se refere às } \\
\text { questões de manejo deste cultivo, quanto no } \\
\text { desenvolvimento de habilidades consideradas } \\
\text { importantes para alcançar um relacionamento de } \\
\text { confiança com o agricultor familiar. }\end{array}$ \\
\hline $\begin{array}{l}\text { Altos custos de } \\
\text { transação }\end{array}$ & $\begin{array}{c}\text { Os custos para se manter os arranjos } \\
\text { produtivos junto aos agricultores familiares } \\
\text { são considerados elevados, tanto pela } \\
\text { dificuldade do gerenciamento de um elevado } \\
\text { número de pequenas propriedades rurais, } \\
\text { quanto pela dispersão geográfica dessas } \\
\text { propriedades. }\end{array}$ & $\begin{array}{c}\text { Investir e capacitar líderes comunitários para que } \\
\text { possam representar os interesses dos agricultores } \\
\text { familiares de mamona. Esses agricultores, por sua } \\
\text { vez, devem ser motivados a participar da gestão } \\
\text { dessas novas organizações, a fim de torná-las } \\
\text { mais representativas. }\end{array}$ \\
\hline
\end{tabular}


Tabela 2. Direcionadores e fatores de competitividade do segmento agrícola.

\begin{tabular}{|c|c|c|c|c|c|c|c|c|}
\hline \multirow{2}{*}{ Direcionadores / fatores } & \multicolumn{4}{|c|}{ Grau de controle ${ }^{1}$} & \multirow{2}{*}{$\mathrm{PD}^{2}$} & \multirow{2}{*}{ Relev. $^{3}$} & \multirow{2}{*}{$\mathrm{PF}^{4}$} & \multirow{2}{*}{ Resultado } \\
\hline & $\mathrm{CF}$ & CG & QC & NC & & & & \\
\hline POLITTICAS SETORIAIS & $\mathrm{X}$ & $x$ & $\mathrm{X}$ & $\mathrm{X}$ & & & 100 & 0,1425 \\
\hline Selo social & & $x$ & & & & $\mathrm{MF}$ & 30 & 0,09 \\
\hline Operacionalização do selo & $x$ & $x$ & & & & $\mathrm{D}$ & 25 & $-0,0375$ \\
\hline Preço de mamona & & $x$ & $x$ & $x$ & 15 & $\mathrm{~F}$ & 30 & 0,045 \\
\hline Políticas de polos & & $x$ & & & & MF & 8 & 0,024 \\
\hline Programa semeando & & $x$ & & & & $\mathrm{MF}$ & 7 & 0,021 \\
\hline FATORES MACROECONÔMICOS & $X$ & $\mathrm{X}$ & $x$ & & & & 100 & $-0,221$ \\
\hline Preço do petróleo & & $x$ & $x$ & & & $\mathrm{~N}$ & 10 & 0 \\
\hline Taxa de câmbio & & $x$ & $x$ & & & $\mathrm{D}$ & 10 & $-0,013$ \\
\hline Tributação & & $x$ & & & 13 & MD & 20 & $-0,052$ \\
\hline Crédito & & $x$ & $x$ & & & MD & 30 & $-0,078$ \\
\hline Endividamento & $x$ & $x$ & & & & MD & 30 & $-0,078$ \\
\hline TECNOLOGIA & $x$ & $x$ & & & & & 100 & $-0,012$ \\
\hline Nível tecnológico geral & $\mathrm{X}$ & $\mathrm{X}$ & & & & $\mathrm{D}$ & 45 & $-0,054$ \\
\hline Cultivares disponíveis & $x$ & $x$ & & & 12 & $\mathrm{D}$ & 25 & $-0,03$ \\
\hline Pesquisa e desenvolvimento & $x$ & $x$ & & & & $\mathrm{MF}$ & 30 & 0,072 \\
\hline GESTÃO & $\mathrm{X}$ & $x$ & $X$ & & & & 100 & $-0,2175$ \\
\hline Custo & $x$ & & & & & MD & 45 & $-0,135$ \\
\hline Assistência técnica & $x$ & $x$ & & & 15 & $\mathrm{D}$ & 35 & $-0,0525$ \\
\hline Qualidade & $x$ & $x$ & $X$ & & & $\mathrm{D}$ & 20 & $-0,03$ \\
\hline RECURSOS PRODUTIVOS & $x$ & $x$ & $x$ & $x$ & & & 100 & $-0,0325$ \\
\hline Sementes & $x$ & $\mathrm{X}$ & $x$ & & & $\mathrm{~F}$ & 15 & 0,0195 \\
\hline Adubo & $x$ & & & & & MD & 5 & $-0,013$ \\
\hline Solo & $x$ & $x$ & & & 13 & $\mathrm{D}$ & 10 & $-0,013$ \\
\hline Água & $x$ & & $x$ & $X$ & & MD & 40 & $-0,104$ \\
\hline Mão de obra & $x$ & & $x$ & & & $\mathrm{MF}$ & 30 & 0,078 \\
\hline ESTRUTURA DE MERCADO & & & & & & & 100 & $-0,14$ \\
\hline Deslocamento espacial & $X$ & $\mathrm{X}$ & $\mathrm{X}$ & & & MD & 40 & $-0,08$ \\
\hline Escala de produção & $x$ & $x$ & $x$ & & 10 & MD & 40 & $-0,08$ \\
\hline Barreiras à entrada e à saída & $x$ & $x$ & $x$ & & & $\mathrm{MF}$ & 20 & 0,04 \\
\hline ESTRUTURA DE GOVERNANÇA & & & & & & & 100 & $-0,096$ \\
\hline Arranjos cooperativos & $x$ & $x$ & $\mathrm{X}$ & & & $\mathrm{D}$ & 10 & $-0,012$ \\
\hline Parcerias e contratos & $x$ & & & & 17 & $\mathrm{~F}$ & 30 & 0,036 \\
\hline Nível de concentração & & $x$ & $x$ & & 12 & MD & 50 & $-0,12$ \\
\hline Ações coletivas de compra & $x$ & & & & & $\mathrm{~N}$ & 10 & 0 \\
\hline INFRAESTRUTURA & & & & & & & 100 & $-0,05$ \\
\hline Disponibilidade de armazéns & $x$ & $x$ & & & 10 & $\mathrm{~F}$ & 50 & 0,05 \\
\hline Disponibilidade de tratores/maquinários & $x$ & $x$ & & & 10 & MD & 50 & $-0,1$ \\
\hline
\end{tabular}

'Grau de controle: CF - Controlável pela Firma, CG - Controlável pelo Governo, QC - Quase Controlável e NC - Não Controlável. ${ }^{2}$ Peso D - Peso do direcionador no total agregado. ${ }^{3}$ Relevância - Avaliação: MD - Muito Desfavorável (valor $=-2$ ), D - Desfavorável (valor $=-1$ ), $\mathrm{N}-\mathrm{Neutro}($ valor $=0$ ), $\mathrm{F}$ - Favorável $($ valor $=+1)$, MF - Muito Favorável $($ valor $=+2)$. ${ }^{4}$ Peso F - Peso do Fator sobre o direcionador.

- Fatores macroeconômicos: os fatores macroeconômicos são muito desfavoráveis para o desenvolvimento de projetos que direcionem o óleo de mamona para o segmento de biodiesel. A tributação existente não é diferenciada para os produtos agrícolas que são direcionados ao setor de biodiesel. 0 agricultor familiar ainda encontra sérias restrições para acesso ao crédito rural em decorrência das elevadas taxas de inadimplência registradas em financiamentos públicos anteriores, além dos riscos econômicos desse cultivo. Segundo profissionais do setor, as exigências dos bancos brasileiros inibem a concessão de crédito aos pequenos agricultores familiares. Em alguns casos, o agricultor não possui nem mesmo o título da terra que cultiva, sendo que esta é uma das primeiras condições para a concessão de financiamento pelos bancos. Além disso, o crédito só é concedido para áreas de plantio situadas em regiões demarcadas pelo zoneamento de risco climático para o plantio de mamona. 
- Tecnologia: o difícil acesso ao crédito atrapalha os investimentos em tecnologia voltados para melhorias nessa cultura. 0 nível tecnológico da produção agrícola de mamona no Brasil ainda pode ser considerado deficiente. As técnicas utilizadas no campo são arcaicas e o manejo agrícola é geralmente inadequado. A quantidade de cultivares comerciais disponíveis no mercado é pequena, sendo outro limitante para a expansão dessa cultura. Em contrapartida, muita pesquisa tem sido direcionada para superar as dificuldades nessa área, o que compensa um pouco o aspecto desfavorável desse direcionador.

- Gestão: a falta de uma gestão de custos de produção eficiente nas propriedades é outro fator que contribui negativamente para a competitividade da produção de mamona no Brasil. Via de regra, o agricultor praticamente não tem acesso a informações técnicas sobre o cultivo da mamona, e seu cultivo é, sobretudo, pautado pelo tradicionalismo e por experiências empíricas passadas de agricultor a agricultor.

A assistência técnica recebida pelos agricultores familiares carece de padronização e as restrições de recursos financeiros e de pessoal limitam a atuação dos técnicos. Esse fator é relevante, pois, segundo Buainain et al. (2007), as atividades agrícolas familiares são fortemente influenciadas por fatores culturais e pela hereditariedade. Isso gera path dependence e contribui para o manejo impróprio desse cultivo.

Em algumas localidades os agricultores familiares têm dificuldades em enquadrar a mamona produzida nas especificações exigidas pelo mercado. As técnicas difundidas para a debulha da mamona são ultrapassadas e apresentam uma série de desvantagens que podem comprometer a qualidade das bagas. De acordo com Savy Filho (2005), as bagas obtidas com técnicas rudimentares de colheita e beneficiamento causam problemas no processamento industrial e favorecem uma conservação pouco eficiente. Apesar de existirem armazéns disponíveis e adequados para a mamona nas regiões estudadas, muitas vezes eles não são usados para sua estocagem.

- Recursos produtivos: projetos sociais têm permitido que sementes de alto rendimento comecem a chegar ao produtor rural. Em que pese esse ponto positivo, esse direcionador ainda é considerado desfavorável à competitividade. Os agricultores familiares não adubam a cultura por conta da incerteza de retorno desse investimento e devido aos altos riscos climáticos. Como esta planta é reputada por produzir em condições adversas, os solos mais pobres são direcionados à sua produção. Adicionalmente, a elevada compactação dos solos em boa parte do semiárido não permite que as águas pluviais sejam absorvidas de maneira eficiente pelo solo.

- Estrutura de mercado: entre os outros grandes gargalos identificados neste trabalho estão a baixa escala de produção e a dispersão espacial dos produtores, a qual dificulta a logística da coleta das bagas de mamona. Por ser uma cultura de baixo custo de implantação e de fácil adaptação, são baixas as barreiras de entrada e saída desse empreendimento. De modo geral, os produtores deixam de plantar mamona no ano subsequente às safras que apresentam valores baixos de mercado e plantam mamona no ano seguinte às safras que apresentam valores mais atrativos. Por esse motivo, há grande oscilação do volume de produção e dos preços de mamona ao longo dos anos. Esta situação evidencia graves problemas de coordenação nesta cadeia produtiva.

- Estrutura de governança: a estrutura de governança é um direcionador desfavorável para a competitividade do segmento do biodiesel. 0 pequeno agricultor familiar brasileiro tem nas relações de confiança atributos importantes na seleção do comprador para os seus produtos. Essa característica faz com que esses produtores prefiram vender seus produtos aos brokers tradicionais da região ao invés de comercializá-los diretamente com as empresas fabricantes de biodiesel. Do ponto de vista do pequeno produtor agrícola e da política social desejada pelo PNPB, a figura do intermediário pode ser vista como sendo desfavorável, pois ele internaliza recursos que poderiam ser captados por uma cooperativa, sendo que tais ganhos seriam reinvestidos no próprio fortalecimento dos agricultores familiares. No entanto, a baixa escala de produção e a dispersão espacial dos produtores tornam complexa a logística da coleta das bagas de mamona e faz com que os acordos comerciais formais de longo prazo fiquem fragilizados frente à forte influência dos intermediários da cadeia da ricinoquímica na comercialização da mamona.

0 pequeno porte dessas propriedades cultivadas com mamona faz com que o número de agricultores familiares que trabalham nesse processo produtivo seja grande, o que dificulta o desenvolvimento do vínculo familiar com os gestores dessa cadeia produtiva de biodiesel. As rotas de coleta da mamona junto aos produtores são definidas diariamente, sendo essa definição baseada, sobretudo, na experiência dos técnicos para identificar as melhores trajetórias para essa movimentação. Apenas para ilustrar, uma das usinas de biodiesel situadas na Bahia trabalha com cerca de 30.000 agricultores familiares (que cultivam várias oleaginosas) somente no estado. Esse número ainda pode ser considerado pequeno perto de um total de 750 mil agricultores familiares do estado. 
Quadro 2. Principais problemas encontrados na produção de mamona voltada para a fabricação de biodiesel e proposições.

\begin{tabular}{|c|c|c|}
\hline Principais problemas & Situação atual & Proposições / desafios \\
\hline $\begin{array}{l}\text { Baixa confiança no } \\
\text { PNPB }\end{array}$ & $\begin{array}{l}\text { A falta de estruturação do PNPB, } \\
\text { principalmente nos primeiros anos do } \\
\text { programa, resultou em preços baixos pagos } \\
\text { pela mamona ao agricultor e descasos de } \\
\text { projetos sociais por parte das usinas. lsso } \\
\text { refletiu no descontentamento e descrença do } \\
\text { produtor familiar em relação ao programa. }\end{array}$ & $\begin{array}{l}\text { Maior fiscalizalização do governo para garantir } \\
\text { o cumprimento dos acordos produtivos firmados } \\
\text { entre usinas e agricultores. Adicionalmente, é } \\
\text { necessário desenvolver ações que visem alcançar } \\
\text { uma relação de maior confiança junto aos } \\
\text { agricultores familiares. }\end{array}$ \\
\hline $\begin{array}{l}\text { Limitações de atuação } \\
\text { das políticas de crédito }\end{array}$ & $\begin{array}{l}\text { Existem linhas de crédito específicas para } \\
\text { fomentos de cultivos do pequeno agricultor. } \\
\text { No entanto, o produtor encontra sérias } \\
\text { restrições para acesso ao crédito rural em } \\
\text { virtude das elevadas taxas de inadimplência, } \\
\text { além dos riscos econômicos e climáticos no } \\
\text { cultivo da mamona. }\end{array}$ & $\begin{array}{l}0 \text { difícil acesso ao crédito faz com que sejam } \\
\text { baixos os investimentos na cultura. Por } \\
\text { esse motivo, há necessidade de criação de } \\
\text { oportunidades de créditos acompanhados de } \\
\text { uma assistência técnica eficiente e focada no } \\
\text { gerenciamento do processo de negócios da } \\
\text { propriedade. }\end{array}$ \\
\hline $\begin{array}{l}\text { Limitações de clima e } \\
\text { solo }\end{array}$ & $\begin{array}{c}\text { As condições edafo-climáticas desfavoráveis } \\
\text { nas áreas produtoras comprometem a } \\
\text { produtividade agrícola. }\end{array}$ & $\begin{array}{l}\text { Melhoria da assistência técnica e fomento ao uso } \\
\text { de corretores do solo. }\end{array}$ \\
\hline Manejo inadequado & $\begin{array}{l}\text { Difusão de técnicas arcaicas e inadequadas no } \\
\text { manejo da mamona. }\end{array}$ & $\begin{array}{l}\text { Há necessidade de difundir o conhecimento } \\
\text { sobre os ganhos com um manejo adequado. A } \\
\text { melhoria da assistência técnica contribuiria para } \\
\text { sobrepor as condições difíceis de solo e região } \\
\text { nas quais a mamona geralmente é cultivada. }\end{array}$ \\
\hline $\begin{array}{l}\text { Presença de } \\
\text { intermediários }\end{array}$ & $\begin{array}{l}\text { A forte influência do intermediário contribui } \\
\text { para os preços instáveis pagos pela mamona } \\
\text { ao agricultor familiar. }\end{array}$ & $\begin{array}{l}\text { Garantir assistência técnica satisfatória, } \\
\text { fornecimento de insumos e preço mínimo } \\
\text { de mercado são ações que podem favorecer } \\
\text { a construção da confiança do agricultor em } \\
\text { relação aos acordos firmados e ao PNPB. Por } \\
\text { consequência, essas ações tendem a enfraquecer } \\
\text { a relação tradicional junto aos brokers e } \\
\text { fortalecer os arranjos sociais junto às usinas. }\end{array}$ \\
\hline Cultivares insuficientes & $\begin{array}{c}\text { As quantidades de cultivares são consideradas } \\
\text { insatisfatórias para atender às diferentes } \\
\text { regiões. }\end{array}$ & $\begin{array}{l}\text { Desenvolvimento e distribuição de cultivares } \\
\text { mais adequados a cada região. Maior } \\
\text { esclarecimento ao agricultor das vantagens } \\
\text { inerentes às sementes de qualidade. }\end{array}$ \\
\hline $\begin{array}{l}\text { Baixa qualidade das } \\
\text { bagas }\end{array}$ & $\begin{array}{c}\text { A qualidade das bagas é baixa em decorrência } \\
\text { das técnicas de cultivo e processamento } \\
\text { empregadas. }\end{array}$ & $\begin{array}{l}\text { Melhoria da assistência técnica, bem como } \\
\text { fomento para a aquisição de maquinário. } \\
\text { Pagamento diferenciado por bagas de maior } \\
\text { qualidade e uniformidade. }\end{array}$ \\
\hline
\end{tabular}

Os arranjos em cooperativas são importantes para a articulação dos milhares de agricultores que poderiam estar envolvidos na produção de mamona. Contudo, o capital social desses arranjos cooperativos ainda é baixo. Embora existam boas iniciativas nessa área, elas são pouco eficientes devido à falta de cultura em cooperativismo nas regiões nas quais predomina o plantio de mamona.

- Infraestrutura: apesar de existirem armazéns disponíveis e adequados para a mamona nas regiões estudadas, muitas vezes eles não são usados para sua estocagem. Praticamente não se encontra o uso de maquinários maiores para o trato da terra, o que também é uma limitação infraestrutural. Há baixa oferta de tratores com preços menos elevados, o que agrava essa situação. Adicionalmente, as condições de conservação das rodovias pelas quais a mamona é transportada são péssimas, encarecendo ainda mais a logística de aprovisionamento das fábricas de biodiesel.

0 Quadro 2 apresenta algumas medidas que vêm sendo tomadas, bem como proposições, para amenizar os entraves apontados nesse elo da cadeia.

\section{Conclusões}

Muitos esforços públicos e privados têm sido empreendidos para viabilizar a produção sustentável de biodiesel a partir da mamona no Brasil. Os maiores entraves para isso parecem situar-se à montante dessa cadeia, ou seja, na própria produção da mamona em condições adequadas para a indústria. 0 estudo apresenta a percepção dos agentes envolvidos nessa cadeia de que os projetos de desenvolvimento social com mamona, no quadro atual, são inviáveis e somente se sustentam por fortes estímulos governamentais. 
A pesquisa demonstrou que são enormes as dificuldades enfrentadas pelas empresas de produção de biodiesel a partir da mamona no Brasil. Os fatores macroeconômicos, gestão e estrutura de mercado são os direcionadores que mais contribuem para um cenário desfavorável à montante dessa cadeia, contribuindo para que o Nordeste se torne pouco atrativo para esse tipo de produção. Profissionais da indústria entrevistados pela pesquisa consideram que a diminuição das cotas de aquisição de 50\% para $30 \%$ para a região do semiárido, prevista na IN n. 01/2009, não será suficiente para viabilizar projetos de desenvolvimento rural na região baseados na produção de mamona destinada à fabricação de biodiesel. 0 elevado custo de estruturação de arranjos produtivos fundamentados na produção da mamona baseada em pequenos agricultores familiares esbarra em uma lógica onde a produção em larga escala conveniente para a indústria confronta-se com a lógica de policultivo de baixa escala de produção característica da agricultura familiar.

A variabilidade nos preços da mamona pagos ao produtor rural, principalmente pelo intermediário voltado para a cadeia da ricinoquímica, é um fator que merece destaque. 0 fortalecimento do capital social dos pequenos produtores agrícolas via, por exemplo, o aumento de ações coletivas de produção e comercialização poderia aumentar o poder de barganha dos produtores frente às indústrias e, dessa forma, se contrapor a essas variações.

Apesar de não terem atingido todos os objetivos pretendidos, os programas regionais de desenvolvimento rural baseados na produção de mamona têm buscado criar mecanismos que dinamizem e sustentem o funcionamento desses arranjos produtivos. Os arranjos em cooperativas permitiriam ao agricultor obter maior articulação no processo de produção e comercialização das bagas. Essa articulação poderia diminuir a influência da figura do atravessador nessa rede, haja vista que ele tem ampliado as dificuldades encontradas pelas usinas de biodiesel para a estruturação de seus arranjos produtivos. Isso faz com que a inclusão de pequenos agricultores em projetos sociais de biodiesel se torne um desafio.

Apesar de haver dificuldades tecnológicas para a produção de biodiesel de mamona que atenda às normas exigidas pela ANP, a falta de sustentabilidade econômica parece ser o principal motivo que leva ao desvio das bagas dos projetos sociais originalmente voltados para a produção de biodiesel para o segmento da ricinoquímica. No cenário atual e até onde se pode vislumbrar, o óleo de mamona tenderá a ser mais valorizado pela indústria da ricinoquímica do que pela do biodiesel.
A título de conclusão, pode-se dizer que a baixa escala de produção, a dispersão espacial das famílias assistidas, as restrições tecnológicas de processo e produto, a baixa produtividade, o manejo agrícola inadequado, a elevada sazonalidade de produção, as secas prolongadas, a assistência técnica deficitária, a grande influência de intermediários da cadeia da ricinoquímica, os preços instáveis, a falta de tradição em associativismo, o alto nível de endividamento dos agricultores rurais e as dificuldades de acesso ao crédito rural estão entre os principais problemas que entravam o desenvolvimento da cadeia de produção de biodiesel a partir da mamona no país. Pelos motivos apresentados, a utilização da mamona para a produção de biodiesel é impraticável no Brasil no curto prazo, parecendo ser uma promessa futura de difícil viabilização.

\section{Referências}

AIGINGER, K. Revisiting an evasive concept: introduction to the special issue on competitiveness. Journal of Industry, Competition and Trade, v. 6, n. 2, p. 63-66, 2006. http:// dx.doi.org/10.1007/s10842-006-9471-x

BATALHA, M. 0., SOUZA FILHO, H. M. Analisando a Competitividade de Cadeias Agroindustriais: uma proposição metodológica. In: BATALHA, M. 0.; SOUZA FILHO, H. M. (Orgs.). Agronegócio no MERCOSUL: uma agenda para o desenvolvimento. São Paulo: Atlas, 2009, p. 1-22.

BATALHA, M. 0.; SILVA, A. L. Gerenciamento de sistemas agroindustriais: definições, especificidades e correntes metodológicas. In: BATALHA, M. 0. (Org.). Gestão agroindustrial. São Paulo: Atlas, 2007. p. 1-62.

BELTRÃO, N. E. M. Informações gerais sobre a cadeia da mamona no Nordeste e o estabelecimento de uma proposta de um projeto de desenvolvimento integrado com ênfase a produção de biodiesel. Campina Grande: Embrapa, 2003. Documento, 122. Disponivel em: <http://www.cnpa.embrapa.br/ publicacoes/2003/D0C122.PDF>. Acesso em: jan. 2008.

BElTRÃO, N. E. M. et al. Clima e solo. In: AZEVEDO, D. M. P.; BELTRÃO, N. E. M. O agronegócio da mamona no Brasil. 2. ed. Brasília: Embrapa, 2007. p. 73-93. Informações Tecnológicas.

BUAINAIN A. M. et al. Tecnologia de gestão e agricultura familiar. In: BUAINAIN, A. M. (Coord.). Agricultura familiar e inovação tecnológica no Brasil: características, desafios e obstáculos. Campinas: Editora da Unicamp, 2007. p. 129-159

BRASIL. Lei no 11.097, de 13 de janeiro de 2005. Dispõe sobre a introdução do biodiesel na matriz energética brasileira. Diário Oficial da República Federativa do Brasil, Brasília, DF, 14 jan. 2005a. Disponível em: <https://legislacao.planalto.gov.br/ legislacao.nsf> Acesso em: dez. 2006.

BRASIL. Instrução Normativa $n^{\circ}$ 1, de 05 de julho de 2005. Dispõe sobre os critérios e procedimentos relativos à concessão de uso do selo combustivel social. Diário Oficial da República Federativa do Brasil, Brasília, DF, 7 jul. 2005b. Disponível em: <http://www.biodiesel.gov.br/docs/Minuta1.pdf>. Acesso em: jan. 2009.

BRASIL. Ministério do Desenvolvimento Agrário. Instrução Normativa $n^{\circ} 1$, de 19 de fevereiro de 2009. Diário Oficial da República Federativa do Brasil, Brasília, DF, 25 fev. 2009a.

BRASIL. Ministério do Desenvolvimento da Indústria e Comércio. Secretaria de Comércio Exterior - MDIC. Aliceweb. MDIC, 2009b. Disponivel em: <www.aliceweb.desenvolvimento.gov. br>. Acesso em: jan. 2009. 
BRASIL. Secretaria de Comunicação de Governo e Gestão Estratégica. Núcleo de Assuntos Estratégicos da Presidência da República NAE. Biocombustíveis. Brasília: NAE, 2004. 234 p. Cadernos NAE, n. 2. Disponivel em: <http://www.biodiesel.gov.br/docs/ Cadernos_NAE_v.2.pdf>. Acesso em: fev. 2008.

CÉSAR, A. S. Análise dos direcionadores de competitividade da cadeia produtiva de biodiesel: o caso da mamona. 2009. 171 f. Dissertação (Mestrado em Engenharia de Produção)-Centro de Ciências Exatas e Tecnologia, Universidade Federal de São Carlos, São Carlos, 2009.

CÉSAR, A. S., BATALHA, M. O. Biodiesel production from castor oil in Brazil: A difficult reality. Energy Policy, v. 38, p. 4031-4039, 2010. http://dx.doi.org/10.1016/j.enpol.2010.03.027

CHARLES, M. B et al. Public policy and biofuel: The way foward? Energy Policy, v. 35, p. 5737-5746, 2007.

DEMIRBAS, A. Importance of biodiesel as transportation fuel. Energy Policy, v. 35, p. 4661-4670, 2007. http://dx.doi.org/10.1016/j. enpol.2007.04.003

DUER, H., CHRISTENSEN P. O. Socio-economic aspects of different biofuel development Pathways. Biomassa and Bioenergy, v. 34, n. 2, p. 1-7, 2009.

FARINA, E. M. M. Q. Competitividade e coordenação de sistemas agroindustriais: um ensaio conceitual. Revista Gestão e Produção, v. 6, n. 3, p. 147-161, 1999.

FERRAZ, J. C. et al. Made in Brazil. Rio de Janeiro: Campus, 1996. $386 \mathrm{p}$.

FISCHER, C.; SCHORNBERG, S. Assessing the Competitiveness Situation of EU Food and Drink Manufacturing Industries: An Index-Based Approach. Agribusiness, v. 23, n. 4, p. 473-495, 2007. http://dx.doi.org/10.1002/agr.20139

GARCEZ, C. A. G.; VIANNA, J. N. S. Brazilian Biodiesel Policy: Social and environmental considerations of sustainability. Energy, v. 34, p. 645-654, 2009.

HASS, M. J.; FOGLIA, T. A. Matérias-primas alternativas e tecnologias para a produção de biodiesel. In: KNOTHE, G. et al. (Eds.) Manual do biodiesel. São Paulo: Edgard Blücher, 2006. p. 46-66.

JANK, M. S. Competitividade do agribusiness brasileiro: discussão teórica e evidências no sistema de carnes. 195 f. 1996. Tese (Doutorado em Administração)-Faculdade de Economia, Administração e Contabilidade, Universidade de São Paulo, São Paulo, 1996.

JUNG, C. F. Metodologia científica - ênfase na pesquisa tecnológica, 2003. Disponivel em: <www.jung.pro.br>. Acesso em: ago. 2007.

KNOTHE, G. A história dos combustiveis derivados de óleos vegetais. ln: KNOTHE, G. et al. Manual do biodiesel. São Paulo: Edgard Blücher, 2006. p. 5-18.

LANDAU, R. Technology, capital formation and U.S. competitiveness. In: HICKMAN, B. G. (Ed.). International Productivity and Competitiveness. New York: Oxford University Press, 1992.
LENSINK, S; LONDO, M. Assessment of biofuels supporting policies using the BioTrans model. Biomassa and Bioenergy, v. 34, n. 2, p. 218-226, 2009. http://dx.doi.org/10.1016/j. biombioe.2009.07.006

MARTIN, L. et al. Agribusiness competitiveness across national boundaries. American Journal of Agricultural Economics, v. 3, n. 5, p. 1456-1464, 1991. http://dx.doi.org/10.2307/1242402

MERRIAM, S. Qualitative research and case study applications. Education. San Francisco: Jossey-Bass Publishers, 1998.

PETERS, J., THIELMANN, S. Promoting biofuels: Implications for developing countries. Energy Policy, v. 36, p. 1538-1544, 2008. http://dx.doi.org/10.1016/j.enpol.2008.01.013

PINHEIRO, A. C.; MOREIRA, A. R. B.; HORTA, M. E. Indicadores de competitividade das exportações: resultados setoriais para o período 1980/88. Rio de Janeiro: IPEA, 1992. Textos para Discussão, 257.

POUSA, G. P. A. G. et al. History and policy of biodiesel in Brazil. Energy Policy, v. 35, p. 5393-5398, 2007. http://dx.doi org/10.1016/j.enpol.2007.05.010

SAVY FILHO, A. Mamona: tecnologia agrícola. Campinas: Emopi, 2005. $105 \mathrm{p}$.

SCHOLZ, V.; SILVA, J. N. Prospects and risks of the use of castor oil as a fuel. Biomass and Bioenergy, v. 32, p. 95-100, 2008. http://dx.doi.org/10.1016/j.biombioe.2007.08.004

SELLTIZ, W. S. et al. Pesquisa nas relações sociais. 10. ed. São Paulo: EdUSP, 1980.

SILVA, C. A. B.; BATALHA, M. 0. Competitividade em sistemas agroindustriais: metodologia e estudo de caso. In: WORKSHOP BRASILEIRO DE GESTÃO DE SISTEMAS ALIMENTARES, 2., 1999, Ribeirão Preto. Anais... Ribeirão Preto: PENSA/FEA/USP, 1999. p. 9- 19.

SILVA, C. A. B.; SOUZA FILHO, H. M. Guidelines for rapid appraisals of agrifood chain performance in developing countries. Rome: FAO, 2007. $111 \mathrm{p}$.

STAATZ, J. M. Notes on the use of subsector analysis as a diagnostic tool for linking industry and agriculture. Michigan: Michigan State University, Department of Agricultural Economics, 1997. p. 1-9.

VAN DUREN, E. et al. Assessing the competitiveness of Canada's agrifood industry. Canadian Journal of Agricultural Economics, v. 39, p. 727-738, 1991.

VAN DUREN, E.; MCKAY, H. Forging strategic alliances in Canada's agrifood sector. Canadian Journal of Agricultural Economics, v. 42, p. 311-326, 1994.

WASSELL JUNIOR, C. S., DITTMER, T. P. Are subsidies for biodiesel economically efficient? Energy Policy, v. 34, p. 3993-4001, 2006. http://dx.doi.org/10.1016/j.enpol.2005.09.024

\section{Analysis of the competitiveness drivers on the biodiesel productive chain: the case of castor bean}

\section{Abstract}

Among the various oilseeds, the castor bean was identified by the National Program for Production and Use of Biodiesel, as the ideal one to promote social development in Brazil's northeast region. However the survey shows that the production of this raw material was not competitive for biodiesel production. The research is qualitative, descriptive and exploratory, and multi-case studies were used for their analysis. The instrument used for data collection was a semi-structured personal interview. Visits to production units were also conducted, which enabled data triangulation. Thus, this paper describes each driver and presents a picture of the competitiveness of both agricultural and industrial productions in this chain. The influence of each driver was evaluated using a Likert scale. The results present a clear view of the competitive segments in the analyzed agribusiness chain.

\section{Keywords}

Biodiesel. Castor. Competitiveness. Family farming. 